\title{
A MODIFIED TECHNIQUE OF RETROGRADE INTUBATION IN A DIFFICULT INTUBATION CASE
}

\author{
S. G. K. Murthy'1, B. Kishan Rao ${ }^{2}$
}

\section{HOW TO CITE THIS ARTICLE:}

S. G. K. Murthy, B. Kishan Rao. "A Modified Technique of Retrograde Intubation in a Difficult Intubation Case". Journal of Evolution of Medical and Dental Sciences 2014; Vol. 3, Issue 34, August 11; Page: 8991-8995, DOI: $10.14260 /$ jemds/2014/3157

INTRODUCTION: Anaesthesiologists will be facing difficult intubating conditions, anticipated or unanticipated, quite frequently, whenever they anaesthetize patients with facio- maxillary injuries, temporo mandibular joint ankylosis, obesity, pregnancy, congenital air-way abnormalities, etc. A large number of aids are available now for intubating in such difficult situations and a lot of techniques have been described in literature for giving anaesthesia for such patients.(1) Use of Bullard laryngoscope in difficult air-way situation was described by Dullenkopf et al 2003,(2) Lighted Wand by Agro et al 2004,(3) Shikani flexible seeing stylet by Agro et al 2005(4) Blind nasal intubation, L M A, Fiber optic laryngoscope by Levitan et al1999.(5) Glydoscope by Lim et al 2005(6). In this case report, we have given one more alternate solution for this problem.

CASE REPORT: 55 years female patient came to Mamata General Hospital with H/o pain in right hypochondrium, vomitings, dyspepsia of 3 months duration. She had no H/o jaundice, but had H/o fever 3 months back, which subsided in a week with some tablets (no records available), She hails from a village in the endemic area for fluorosis in Andhra Pradesh. Her neck was fixed in a bent position and no flexion, extension or rotation movements of the neck were possible. Her lumbar spine was also stiff and no movements were possible. Upper and lower limb joints were stiff and painful. Ultrasound examination of abdomen revealed Cholelithiasis, and she was posted for elective Cholecystectomy under general anaesthesia.

Airway examination: No neck movements possible, as her cervical spine was stiff and bent forwards. When she was asked to open mouth fully, we could see only hard palate (Mallampatti gr 1V). There was gingival hyperplasia also. Inter insisural distance was $2 \mathrm{cms}$, mento hyoid distance-2 cms, mento sternal distance $5 \mathrm{cms}$.

INVESTIGATIONS: Within normal limits except for elevated ESR (65 mm for first hour). Weight of the patient- $65 \mathrm{Kg}$. The Patient was accepted for cholecystectomy under general anaesthesia with ASA II risk.

PREMEDICATION: Fentanyl 50 micro grams, Midazolam 2 mgs, Glycopyrrolate 0.2 mgs were given intra muscularly half an hour before shifting patient into the Operating Room.

ANAESTHESIA: In the operation theatre I V line secured with No 18 gauze intracath, and $5 \%$ Dextrose in Normal Saline drip was started. Monitors connected were- Pulse, BP, ECG, \& Pulse oxymeter. Pre oxygenation was given with $100 \%$ oxygen for five minutes, by Bain's (adult) anaesthesia circuit by mask. 
We kept Classic L M A size 3, emergency tracheostomy set, and jet ventilator ready as alternate techniques. We kept Anaesthesia machine, anaesthesia and emergency drugs, endotracheal tubes of different sizes and Macintosh laryngoscope ready.

The patient was advised to gargle $5 \mathrm{ml}$ of $2 \%$ Lignocaine viscous, for 2 minutes, and spit it out. Posterior pharyngeal wall was sprayed with $2 \mathrm{ml}$ of $4 \%$ lignocaine solution. The superior laryngeal nerve block was given bilaterally with $2 \mathrm{ml}$ of $1 \%$ lignocaine.

Trans tracheal spray was given with $1 \mathrm{ml}$ of $4 \%$ lignocaine and the patient was asked to cough out as soon as the needle was removed. With this the airway was completely anaesthetized, and patient was in a position to tolerate and accept all our further maneuvers. Meanwhile Oxygenation by mask was continuing whenever possible and $100 \%$ oxygen saturation was maintained throughout.

Skin over trachea was infiltrated with $1 \mathrm{ml}$ of $1 \%$ lignocaine.

A guide wire was made as a loop and introduced into oropharynx from the open mouth\& kept ready to receive guide wire coming from trachea through the glottis in retrograde way (Arya's technique). ${ }^{7}$ Trachea was punctured with 16 gauze Tuohay epidural needle below the cricoid cartilage after local infiltration with 1 cc of $1 \%$ lignocaine. After aspirating air, guide wire was introduced into trachea, and guided through glottis into the oropharynx and into the oropharyngeal loop which was introduced earlier.

The tuohay epidural needle was removed keeping the guide wire in situ. The proximal end of guide wire which was introduced through tracheal puncture was brought out of the oral cavity with the aid of the pharyngeal loop (Arya's technique) ${ }^{7}$. Oxygenation with $100 \%$ oxygen by mask was administered for one more minute to make sure that oxygen saturation was maintained at $100 \%$.

Ventilating cannulated bougie (Cook's bougie) was introduced from oral cavity into trachea over the guide wire and oxygenation continued through cannulated bougie.

Both ends of guide wire were left without traction. 6.5 cuffed portex endotracheal tube was introduced over cook's bougie, and tried to push it into the trachea. When it was hitching near epiglottis level, tube was withdrawn about $1 \mathrm{~cm}$, rotated $90^{\circ}$ in clockwise fashion, introduced forwards once again, and rotated back by $90^{\circ}$ in anti-clockwise fashion. Thus we could overcome hitching of endotracheal tube near epiglottis.

With a small push further, the endotracheal tube could be successfully introduced into the trachea. 100\%0xygenation continued through an endotracheal tube with Bain's anaesthesia circuit. Till this time patient was conscious and cooperating with all our efforts.

Then general anaesthesia was induced with a sleep dose of Thiopentone sodium $(200 \mathrm{mg}) \mathrm{Iv}$, patient was paralyzed with Vecuronium $4 \mathrm{mg}$, ventilated with $60 \%$ Nitrous oxide and $40 \%$ oxygen by Bain's anaesthesia circuit. When the patient was fully anaesthetized, surgeon was allowed to operate. Total procedure of surgery lasted for 2 hours.

Required IV infusion fluids were infused to maintain normal BP and pulse rate, and top up doses of Vecuronium, \& Fentanyl were given whenever required. Oxygen saturation was maintained $100 \%$ throughout the procedure. At the end of the procedure, the neuro muscular block was reversed with Glycopyrrolate $0.5 \mathrm{mg}+$ Neostigmine $2.5 \mathrm{mg}$ I v.

When the patient was fully conscious and breathing spontaneously, she was extubated, and was given $100 \%$ oxygen by mask for 5 minutes to avoid diffusion hypoxia. After full recovery, the patient was shifted to post-operative ward, kept in 30degrees prop up position, and oxygenation was 
given by Hudson's mask. Postoperative period was uneventful. The patient needed \& received only Inj Diclofenac $75 \mathrm{mgs}$ in for post-operative analgesia. The patient was discharged from the hospital in 8 the post-operative day in reasonably good health and full satisfaction.

DISCUSSION: Retrograde intubation is one of the safe invasive technique which is many times less traumatic than so called non-invasive techniques like blind nasal intubation, or intubation with the aid of the fiberoptic bronchoscope (especially in untrained hands) (Weksler et al(8). Since its first invention by Butler and Cerillo in 1960,(9) a number of modifications were reported in the literature as solutions to particular problems.

Usage of Fiber optic laryngoscope as an aid for retrograde intubation was reported by Biswas and Bhattacharya 2005.(10) In situ combitube as a guide to retrograde intubation was described by Harrison et al in 2005.(11) Demonstration of retrograde intubation in a mannequin was described by Van Stralen et al 1995.(12) A modified technique of retrograde intubation in children using a naso pharyngeal airway was described Sheila Kamat et al 2008.(13)

Even after the successful introduction of the guide wire in trachea and bringing it out through mouth via glottic opening, endotracheal tube introduction over guide wire can fail and can produce trauma. When both ends of guide wire are pulled up tightly and endotracheal tube is introduced over it and pushed into trachea, it can hitch near epiglottis or glottis, and can produce trauma. As a solution to this problem, Vithal K Dhulkhed 2008.(14)

Described double guide wire technique, in which a second guide wire was introduced by the side of first guide wire, use it to pull the epiglottis up, and first guide wire was used as a guide to introduce the endotracheal tube. Even then endotracheal tube can hitch somewhere and cause trauma (Gill et al 2005).(15) Moreover, two tracheal punctures are required for this technique.

Retrograde intubation done in a planned way in well prepared patient will be smoother and less traumatic than all other invasive and non-invasive alternative techniques in the majority of situations. General anaesthesia for retrograde intubation is alright, provided endotracheal intubation is done fast without delay.

But in difficult airway situation, time of endotracheal intubation is likely to be long, and patients can likely become hypoxic if the patient is paralyzed. General anaesthesia with spontaneous respirations can buy some more time for anaesthetists to try endotracheal intubation, but laryngospasm, bronchospasm, and respiratory obstruction with secreations \& blood are dangers still.

If the patient is conscious, cooperative, and air way is sufficiently anaesthetized, patient can breathe, can cough out secretions and this gives more length of time for anesthetists to try and establish a clear airway (endotracheal intubation) (Nibedita Pani et al 2009)(16). For our patient, general anaesthesia was given only after establishing clear and safe airway by endotacheal intubation in retrograde intubation technique.

Pulse rate, respirations, B P and oxygen saturation maintained within normal limits, as we selected local anaesthesia for retrograde endotracheal intubation, oxygenating the patient whenever required and given general anaesthesia only after successful endotracheal intubation.

Fluorosis is an endemic disease in Nalgonda district of Andhra Pradesh. The cause for this disease is the presence of high fluorine content in ground drinking water in this area. Manifestations of this disease are painful and swollen joints, reduced and restricted mobility of all joints in the body. It is not uncommon to see stiff and bamboo like vertebral column, in these patients. 
Spinal analgesia is not possible in these cases, as lumbar puncture needle cannot puncture inter vertebral spaces in lumbar region. Endotracheal intubation will also be equally difficult as extension of the Atlanta occipital joint is restricted. Assisting devices like Fiber optic bronchoscope, LMA, retrograde intubation set and tracheostomy set, are mandatory for giving anaesthesia to these patients.

CONCLUSION: Cannulated ventilating bougie over guide wire introduced into trachea in a retrograde way, can help in endotracheal intubation in difficult airway situation. Local and topical anaesthesia is safest in difficult airway situation (Nibedita Pani et al), ${ }^{16}$ and it can give more time for anaesthetists to try, and to succeed.

\section{REFERENCES:}

1. Hung 0 and Law J A., Advances in air way management., Can. Jr. of Anaest 2006; 53 (6): 62831.

2. Dullenkopf A, Lamessic. G, Gerber. A, Weiss. M, Video enhanced visualization of larynx and intubation with Bullard laryngoscope- equipment report., Can. Jr. Anaest2003; 50: 507-10.

3. Agro F E, Jolenelli A, Ghehrard S., Planned lighted wand intubation in a patient with a known difficult air way(letter)., Can Jr. Anaest 2004; 51: 1051-2.

4. Agro F E, Antolenni S, Cataldo R, Use of Shikani flexible seeing stylet for intubation via intubating laryngeal mask airway.(letter) Can. Jr. of Anaesth 2005; 52: 657-8.

5. Livitan R M, Kush S, Hollander J E., Devices for difficult airway management in academic emergency department., Ann. Emerg. Med.1999; 33: 694-98

6. Lim I J, Lim Y, Liu E H C., Evaluation of ease of intubation with Glydoscope, or Macintosh laryngoscope, by Anaesthetists in simulated easy and difficult laryngoscopy., Anaesthesia 2005; 60 (2): $180-3$

7. Arya V K, Datta A, Chari P., Difficult retrograde endotracheal intubation, utility of pharyngeal loop., Anaesth. Analg.2002; 94: 470-3.

8. Weksler N, Klein M, Weksler D, Sidelnic C, Chroni I, Rozentseig V, Brill S, Gurman G M, Ovadia L., Retrograde tracheal intubation beyond fiber optic endotracheal intubation., Acta. Anaest. Scand., 2004; 48 (4): 412-16.

9. Buttler F S, Cerillo AA, Retrograde tracheal intubation. Anaesth. Analg., 1960; 39: 333-8.

10. Biswas B K, Bhattacharya P, Joshi S, Juladhar V R, Banival S; Fiberoscope aided retrograde placement of guide wire for tracheal intubation in patients with limited mouth opening., Br. Jr. of Anaesth 2005; 94: 128-31.

11. Harrison WL, Bettrand M L, Andeug S K, Clark J A, Retrograde intubation around an insitu combitube, a difficult air way management strategy., Anaesthesiology 2005; 102 (5): 1061-62

12. Van Stralen DW, Rogers M, Perkin RM, Fea S., Retrograde intubation training using a mannequin., Am. Jr. Emerg Med., 1995; 13: 50-52.

13. Kamat S, Raju M, Gupta R , Kamat S., Modified technique of retrograde intubation in temporo madibular Joint ankylosis., I J A; 2008; 52 (2): 196-8.

14. Dulkhed V K. Retrograde intubation in temporo mandibular joint ankylosis, a double guide wire technique, I J A 2008; 52 (1): 90-92. 


\section{CASE REPORT}

15. Gill M, Midden M J, Green SM., Retrograde endotracheal intubation an investigation of indications, complications, and patient outcome., Amer. Jr. of Emerg Med., 2005; 23: 123-6.

16. Pani N, Rath S K., Regional and topical anaesthesia for upper air ways., I J A 2009; 53 (6): 641-8.

\section{AUTHORS:}

1. S. G. K. Murthy

2. B. Kishan Rao

\section{PARTICULARS OF CONTRIBUTORS:}

1. Professor and HOD, Department of Anaesthesiology, Mamata Medical College, Khammam, A. P.

2. Associate Professor, Department of Anaesthesiology, Mamata Medical College, Khammam, A. P.

\section{NAME ADDRESS EMAIL ID OF THE \\ CORRESPONDING AUTHOR:}

Dr. S. G. K. Murthy,

Professor and HOD,

Department of Anaesthesiology, Mamata Medical College,

Khammam-507002, A. P.

Email: dr.sgkmurthy@gmail.com

Date of Submission: 24/07/2014.

Date of Peer Review: 25/07/2014.

Date of Acceptance: 04/08/2014.

Date of Publishing: 08/08/2014. 